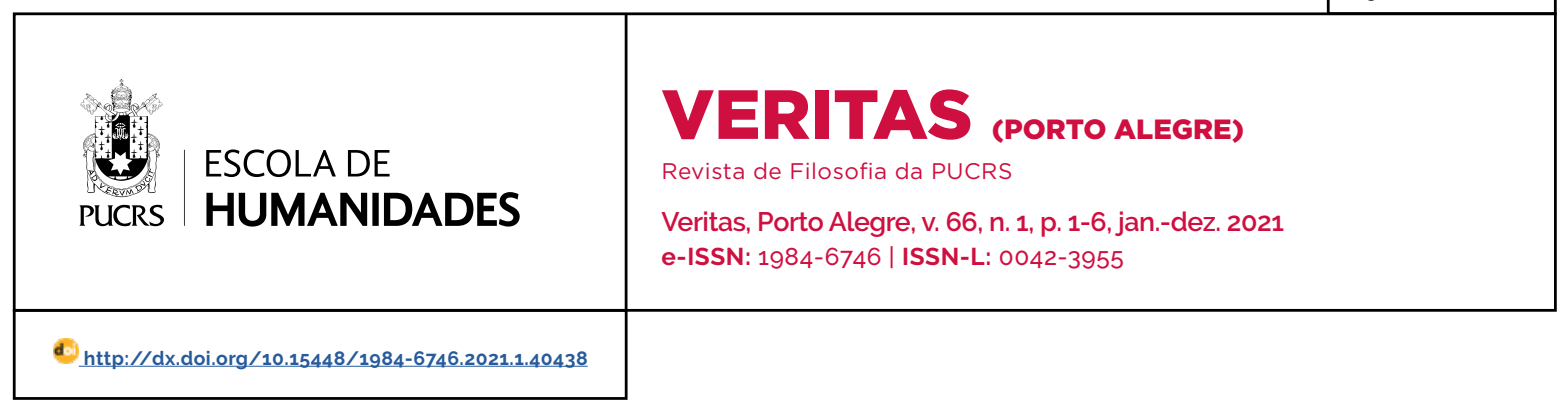

RESENHA

\title{
Democracia popular, sem eleições nem políticos
}

\author{
Popular democracy, without elections or politicians \\ Democracia popular, sin elecciones ni politicos
}

\section{Sebastián Rudas ${ }^{1}$}

orcid.org/0000-0003-4263-5584

sebrudas@gmail.com

Recebido em: 22 mar. 2021.

Aprovado em: 18 jul. 2021.

Publicado em: 27 ago. 2021.
LANDEMORE, Hélène. Open Democracy. Reinventing Popular Rule for the Twenty-First Century. New Jersey: Princeton University Press, 2020.

Nos últimos anos, são frequentes os diagnósticos sobre a crise da democracia. É comum que se afirme que enfrentamos uma crise de representatividade democrática. Na verdade, a "crise" pode ser uma boa notícia, pois poderia indicar o surgimento de movimentos populares reclamando um espaço na política usurpado por elites oligárquicas que governam exclusivamente a partir dos seus interesses. O estallido social chileno de 2019 pode ser lido nesta chave: um movimento social cansado da elite tecnocrática que não cumpriu a promessa liberal de ascensão social e econômica como consequência do esforço individual. Observadores do estallido afirmaram que se tratava de um movimento sem líderes que promovia formas diretas de participação, contrárias não só ao modelo elitista de representação vigente no país, mas também a qualquer modelo de representação democrática. Similarmente a vários movimentos sociais, o movimento defendia a democracia direta. No entanto, a crise da representação não é só oportunidade para governos populares. Oligarcas racistas, homofóbicos e misóginos também encontraram na crise oportunidade para ocupar cadeiras presidenciais. A narrativa deles é similar: afirmaram a usurpação do poder político por uma elite não representativa do povo. Eles seriam as genuinas encarnações do povo, representando seus interesses. Nesse cenário, já foi diagnosticado que a crise corresponde à incapacidade das elites políticas em exercer sua função como gatekeepers (LEVITSKY; ZIBLATT, 2018). De acordo com Levitsky e Ziblatt, evitar a morte das democracias - ou seja, do modelo representativo eleitoral das democracias liberais - consiste em fortalecer às elites politicas tradicionais. Enquanto esses autores querem preservar o sistema representativo eleitoral das democracias liberais que conhecemos hoje, o estallido social chileno procurou modelos democráticos de governo popular.

Em Open Democracy, Landemore também toma como ponto de partida o diagnóstico da crise de representatividade. Porém, ela considera que a
Artigo está licenciado sob forma de uma licença Creative Commons Atribuição 4.0 Internacional. 
saída da crise não é nem a democracia direta nem o resgate da democracia liberal. A solução é, pelo contrário, promover uma democracia representativa popular sem eleições. Landemore defende a "democracia aberta", um modelo de democracia representativa que concebe a igualdade política em termos de igual oportunidade para aceder às instâncias do poder político. Igualdade política significa que a origem econômica, rasgos da pessoalidade, ou conexões pessoais não são determinantes nas probabilidades de uma pessoa aceder às instâncias as quais se define a pauta política, propõem-se políticas públicas, e escrevem-se e votam-se leis. A igualdade política é alcançada, diz Landemore, se adotada a lotocracia (seleção aleatória) como mecanismo de seleção de representantes.

Landemore, professora de teoria política na Universidade de Yale, realiza pesquisa, entre outras áreas, em teoria democrática e epistemologia política. Seu livro de 2013, Democratic Reason, argumenta em favor da superioridade epistêmica das decisões coletivas. Como veremos na sequência, a sua tese serve de base para justificar um sistema de democracia aberta tão inclusivo que garante iguais oportunidades para todas as pessoas - independentemente dos seus conhecimentos técnicos e sobre política - participarem não só nas deliberações para a tomada de decisões, mas também na agenda setting. A proposta institucional mais chamativa da democracia aberta é a adoção da seleção aleatória como mecanismo para a seleção de representantes, que deveriam atender ao chamado como uma obrigação cívica democrática - percebendo um salário generoso - e que seriam escolhidos para deliberar e decidir sobre temas específicos por periodos determinados, sempre acompanhados por especialistas técnicos que ofereceriam informações necessárias para tomar decisões fundamentadas.

A defesa da democracia aberta é proposta em duas frentes, uma normativa e a outra empírica. A primeira (caps. 2, 3, 4, 6 e 8) consiste em mostrar que há espaço conceitual para conceber a democracia nos termos propostos por Landemore e, ainda, que esses termos se mostram mais atrativos do que os termos que utilizamos para defender outras versões da democracia. A defesa empirica da democracia aberta (caps. 5, 7, e 9) consiste em mostrar diversas experiências de exercícios similares ao paradigma da democracia aberta.

Para entender o modelo proposto por Landemore é útil revisar a crítica aos modelos representativo eleitoral e direto. Percebe-se o tom da crítica à democracia representativa eleitoral na abordagem realizada sobre a democracia deliberativa, "a visão mais atrativa até agora da democracia representativa" (LANDEMORE, 2013. p. 36). Landemore se concentra no modelo habermasiano, do qual destaca a identificação de dois tipos de deliberação - um que acontece no grande público e outro nas instâncias de tomada de decisão - interligados graças à atuação dos partidos políticos e associações civis. Mesmo se essa conexão é eficaz e responsiva aos interesses do grande público (cidadãos ordinários), Landemore entende esse modelo como inaceitavelmente elitista, no qual há "separação entre uma elite de oficiais elegidos, juizes indicados, e corpos administrativos que governa [...] e a massa dos cidadãos ordinários" (2013, p. 38). A democracia aberta seria preferivel porque evita o elitismo da democracia deliberativa eleitoral.

Um segundo argumento contra a democracia deliberativa habermasiana mostra que suas dimensões eleitoral e deliberativa demandam virtudes civicas mutuamente contrárias (2013, p. 39). A democracia eleitoral funciona em torno de eleições, mobilizadas por partidos que articulam de maneira relativamente coerente plataformas políticas sobre temas complexos em termos acessiveis para o entendimento dos cidadãos ordinários. A política eleitoral espera engajamento partidário, ou seja, a aceitação mais ou menos acritica das plataformas dos partidos. Em contraste, a democracia deliberativa promove virtudes civicas distintas: abertura ao diálogo, revisão das próprias crenças, e uma atitude não dogmática e não partidária. A democracia aberta não enfrenta esse problema, pois prescinde de eleições e, portanto, pode promover virtudes civicas deliberativas. 
A alternativa à democracia representativa eleitoral é a democracia direta, que rejeita qualquer forma de representação e propõe a participação dos cidadãos ordinários em assembleias e instâncias de decisão. Landemore identifica vários problemas nessa visão da democracia, dos quais apresento o que considero mais sugestivos.

Landemore argumenta que a democracia direta atribui pouco poder político aos cidadãos ordinários, pois é reduzido à expressão da última palavra nas decisões (o voto). Essa característica é visivel na obra de Rousseau, um dos mais famosos defensores da democracia direta. Embora no Contrato Social ele tenha rejeitado qualquer forma de representação, nas suas recomendações políticas para as nações da Polônia e Córsega sugere, de forma intrigante, a eleição de governos aristocratas. De acordo com as interpretações exploradas por Landemore acerca dessa aparente contradição, a chave de leitura estaria em compreender que Rousseau adota uma distinção - presente na ideia hobbesiana que Richard Tuck chamou de "soberano dormente" (TUCK apud LANDEMORE, 2013, p. 57) - entre governo e soberania. A soberania é interpretada em termos do poder de ter a última palavra em uma decisão, e o governo é entendido como o exercicio político que conduz às decisões (formulação de pauta política e deliberação sobre ela). De acordo com essa interpretação, o povo é o soberano e exerce seu poder na aprovação das leis fundamentais (a constituição), e os delegados do povo (políticos ou aristocratas) encarregam-se de interpretar a vontade popular registrada na constituição. Assim, faz sentido a recomendação de Rousseau para a Polônia e Córsega: o povo é soberano e é governado por uma aristocracia, que, Landemore ressalta, teria legitimidade democrática, já que é autorizada pela maioria dos governados. Na democracia direta formulada por Rousseau, abre-se a possibilidade de governos elitistas ainda se o povo preserva a soberania para autorizar governadores e legisladores.

Uma vez que a implausibilidade da democracia direta e da democracia representativa eleitoral foi explicitada, precisamos analisar se a demo- cracia aberta é conceitualmente coerente e se é mais plausivel do que suas alternativas. Nesta análise, acredito, encontramos a maior riqueza teórica do livro. A autora define e defende de maneira inovadora conceitos importantes para a teoria política, tais como "legitimidade", "representação", e, provavelmente o mais importante, "democraticidade" (caps. 4 e 5).

A ideia de consentimento voluntário é central na explicação da origem da legitimidade do poder político nas democracias eleitorais. Os resultados das eleições são considerados como expressões da vontade "da maioria" sobre quem está autorizado para governar. No entanto, essa ideia não convence Landemore (2013, p. 83-85). Basear a legitimidade do poder político no consentimento "da maioria" só serve para explicar a origem da legitimidade do poder outorgado aos representantes por um setor da população. Deixa-se sem explicação a origem da legitimidade desse poder frente às pessoas que não compõem essa maioria. Haveria legitimidade plena, diz ela, só se quem vence nas eleições recebe autorização unânime nas urnas, o que é praticamente impossivel (ou suspeito, se acontecer). Uma resposta a essa crítica poderia ser que, na medida em que há acordo nas "regras do jogo" (quem obtém a maioria dos votos ganha a autorização de toda a população), os representantes têm legitimidade mesmo que não obtenham o voto de todas as pessoas que participam nas eleições. Essa resposta, mostra Landemore, é problemática, pois, pela mesma lógica da objeção, deveríamos esperar unanimidade na aceitação das regras do jogo (por exemplo, na Constituição). Não há registro parecido na história. Ademais, se essa resposta fosse aceita, estariamos admitindo uma visão da democracia pouco plausível, pois regimes monárquicos e oligárquicos poderiam ser justificados da mesma forma.

Se a representação eleitoral não é plausivel, qual a alternativa? Landemore responde: adotemos uma concepção não eleitoral da representação politica. Devido à naturalização da nossa crença que vincula conceitualmente "democracia" com "eleições", é importante, portanto, fazer explícito porque é 
possivel e plausivel conceber uma concepção não eleitoral da representação democrática.

O primeiro passo é oferecer uma definição de "representação". Para ela, representação é o fato de um grupo julgar que uma pessoa, ao invés de alguém mais, comparece com o objetivo de realizar uma atividade determinada (2013, p. 86). Por não ser normativa, essa definição não nos informa sobre as credenciais democráticas e de legitimidade da representação de um agente. Precisamos, portanto, estabelecer as condições sob as quais a representação politica ganha essas credenciais. As credenciais democráticas (ou democraticidade), estão determinadas em função das características do mecanismo de seleção de representantes. A representação é democrática se o mecanismo é igualitário e inclusivo, isto é, se a pessoa obteve a distinção num processo seletivo do qual ninguém foi excluido e em que todas participaram em condições de igualdade. A representação é não democrática se o processo seletivo não é inclusivo ou igualitário; por exemplo quando estabelece critérios seletivos meritocráticos, oligárquicos ou aristocráticos. Por sua parte, Landemore considera que uma das fontes da legitimidade está determinada em função do mecanismo por meio do qual quem representa obteve a autorização para representar. Se o mecanismo é majoritário, a legitimidade é democrática, mas se o mecanismo não é majoritário - e a pessoa que afirma ter o direito de representar ganha a autorização de alguma forma - a legitimidade é não democrática.

Uma conclusão importante deriva-se da distinção entre "democraticidade" e "legitimidade". Na democracia eleitoral, as representantes têm legitimidade democrática, mas não contam com democraticidade (situação similar acontece na interpretação do governo aristocrata da Polônia e Córsega). O sistema de representação eleitoral é um mecanismo que expressa a preferência da maioria, mas que seleciona entre um grupo reduzido de participantes: políticos profissionais, que com frequência são oligarcas, têm excelentes conexões políticas, e são particularmente carismáticos (2013, p. 89). Em contraste, na democracia aberta, os re- presentantes (não eleitos por voto) contam tanto com legitimidade democrática - porém indireta, pois depende da maioria aprovar o mecanismo de seleção - quanto com democraticidade - pois procuram-se mecanismos de representação nos quais todo o demos tem a mesma probabilidade de adquirir poder político. Um sistema político cujos representantes contam com um alto nível de democraticidade é um governo popular.

Landemore ilustra sua proposta analisando o processo constituinte da Islândia (2010-2013). no qual uma constituição nacional foi escrita por políticos amadores, com a participação do grande público através de crowdsourcing, e a partir das reflexões de um grupo de 950 cidadãos ordinários selecionadas aleatoriamente para definir os valores políticos da sociedade islandesa (cap. 7). Após análise dos cinco princípios da democracia aberta (cap. 6), Landemore conclui que a experiência Islandesa oferece um exemplo sobre a viabilidade de implementação da democracia aberta. Brevemente, os cinco principios são: a) O princípio de "direitos de participação": na democracia aberta institui-se uma concepção positiva da liberdade de acordo com a qual a entrada de cidadãos ordinários na política é promovida em condições de igualdade. Uma das características do processo na Islândia foi que procurou diversas formas de participação de cidadãs ordinárias; b) o "princípio de deliberação": um dos elementos mais interessantes da proposta de Landemore é a sua ênfase na promoção de deliberação sobre assuntos políticos por parte de pessoas que não são políticas professionais. Em sintonia com sua pesquisa anterior, Landemore (2013) considera que é a diversidade dos individuos que compõem um grupo, e não sua expertise, o que define a inteligência do grupo e, portanto, sua capacidade para resolver problemas complexos. No processo islandês houve vários momentos de genuina deliberação, tanto nos grupos de representantes quanto na comunidade do crowdsourcing; c) o "principio da maioria": dos cinco principios, este foi o único que não foi observado no processo islandês, condenando-o ao fracasso. Para Landemore, esse fracasso só sugere a urgência da sua 
proposta, pois foi no momento em que políticos profissionais deviam ratificar a constituição que esta foi abandonada; d) O princípio da "representação democrática": a democracia aberta opta por mecanismos que garantam a igualdade nas probabilidades para ingressar nas instâncias do poder político. Este é o princípio com maior presença durante o processo islandês, uma vez que praticamente todas as cidadãs tiveram igual oportunidade para participar e, quando o fizeram, acessaram ao poder político em condições de igualdade; e) o principio da "transparência" estabelece mecanismos de accountability. Em cada uma das etapas do processo foi possivel para todas as pessoas revisar as atividades dos representantes. Diferentemente da forma como usualmente são escritas as constituições (um grupo de homens reunidos de porta fechada), na Islândia o processo inteiro teve as portas abertas e, portanto, a vigilância podia ser constante.

A proposta da democracia aberta é ousada porque desafia tanto crenças quanto práticas bem consolidadas que modelam a forma como concebemos a democracia. Por este motivo, há uma série de objeções relativamente comuns: a) só pode funcionar em países pequenos; b) só pode funcionar em paises homogêneos; c) é arriscada porque deixa nas mãos de pessoas amadoras a tomada de decisão sobre assuntos complexos; d) é perigosa porque abre a possibilidade de consolidar maiorias não liberais ou não democráticas; e) não providencia mecanismos para evitar que grupos de interesse capturem a política; ou f) não tem mecanismos de accountability. O capitulo 8 responde essas questões.

Uma enumeração rápida dá uma ideia do tipo de respostas oferecidas por Landemore: a) a Índia e o Brasiljá implementaram com sucesso medidas similares à democracia aberta, nas quais cidadãs ordinárias deliberaram e propuseram, de forma massiva, iniciativas de políticas públicas. Portanto, não é verdade que só em paises pequenos e ricos a democracia aberta pode funcionar; b) atualmente está em curso na França um promissor experimento deliberativo com pessoas selecionadas aleatoriamente, sugerindo que a homogeneidade cultural ou religiosa não é determinante para a viabilidade da democracia aberta; c) é verdade que a política atual é complexa, contudo, a complexidade traz também muita incerteza. Em estudos prévios, Landemore (2013) já arguiu que em contextos de alta complexidade e incerteza, soluções propostas por grupos compostos por pessoas não experts e com experiências de vida diversas conseguem superar soluções propostas por grupos de experts (com frequência, bastante homogêneos), d) pensar que as instituições liberais contra majoritárias são as únicas protetoras de direitos individuais é desconhecer a longa história de proteção de liberdades individuais em outros contextos; e) os grupos de interesse teriam maiores dificuldades para capturar o sistema político devido à ausência de eleições, pois, por exemplo, não há financiamento de campanha por parte desses grupos. Por fim, f) nada impede que sejam estabelecidos mecanismos para garantir accountability dos representantes.

A proposta de Landemore, inscrita numa tendência contrária às eleições e favorável à lotocracia, é atrativa se pensada como mecanismo para realizar o ideal da igualdade politica. Num contexto de democracias oligárquicas, propostas desse tipo parecem urgentes. O que perdemos se aceitamos a proposta da democracia aberta? A classe dos politicos profissionais e, provavelmente, os partidos políticos, pois sua razão de existência, as eleições, cessaria de existir. No contexto atual de desprestígio dessas entidades políticas, a perda parece ganância. Contudo, os partidos políticos (e associações funcionalmente similares) são instituições importantes nas democracias, pois eles não só articulam plataformas políticas e respondem aos interesses do povo, mas também mobilizam recursos e articulam ideologias e projetos políticos de longo alcance. Eles cumprem uma função agregadora de esforços coletivos e motivam as pessoas inclinadas pelo ativismo e engajamento político a procurar estratégias para obter poder político. Esse entusiasmo coletivo próprio dos partidos políticos e dos movimentos sociais - quando cumprem sua função normativa numa democracia - perder-se-ia na democracia 
aberta. No modelo de Landemore, poderiamos especular que o poder político seria ocupado por cidadãs moderadamente engajadas em política. É provável que diminuiria o caráter de confrontação da política democrática como a conhecemos hoje, bem como o fôlego da militância, que muitos consideram essencial para encaminhar as transformações profundas necessárias para a promoção de uma sociedade justa. Provavelmente, as prospectivas de outro estallido social diminuiriam. Alguém poderia dizer que essa é uma consequência do governo popular; e alguém mais poderia rebater que perder-se-ia a possibilidade de combater as injustiças sociais que requerem engajamento coletivo, militante e partidário.

\section{Referências}

LANDEMORE, Hélène. Open Democracy. Reinventing Popular Rule for the Twenty-First Century. New Jersey: Princeton University Press, 2020.

LANDEMORE, Hélène. Democratic Reason: Politics, Collective Intelligence, and the Rule of the Many. New Jersey: Princeton University Press, 2013.

LEVITSKY, Seteven; ZIBLATT, Daniel. How Democracies Die. New York: Crown, 2013.

\section{Sebastián Rudas}

Doutor em Teoria Política pela LUISS Guido Carli, em Roma, Itália, com estágios de pesquisa de pós-doutorado na Universidade de São Paulo (USP), em São Paulo, SP, Brasil, e na Universidade Católica de Leuven. Pesquisador na área de filosofia e teoria política.

\section{Endereço para correspondência}

\section{Sebastián Rudas}

Rua Eduardo Gut 191, Casa 2

Jardim Maria de Fátima, 13220465.

Várzea Paulista, SP, Brasil

Os textos deste artigo foram revisados pela Poá Comunicação e submetidos para validação do autor antes da publicação. 